\title{
Study on Corrosion Behavior of Rebar HRB335 in NaCl Solution
}

\author{
Ping Li \\ Department of Civil Engineering, Luoyang Institute of Science and Technology, Luoyang, China \\ e-mail: eappol@163.com
}

Keywords.rebar; $\mathrm{NaCl}$ solution; corrosion rate; corrosion morphology

\begin{abstract}
The corrosion behavior of rebar HRB335 in 0.5 wt.\%, 1.5 wt.\% and 3.5 wt.\% NaCl solutions was investigated by corrosion rate calculation and corrosion morphology observation. The results showed that, with the increase of corrosion time from $240 \mathrm{~h}$ to $720 \mathrm{~h}$, the corrosion rate of rebar HRB335 in each $\mathrm{NaCl}$ solution increases. With the increase of $\mathrm{NaCl}$ solution concentration, the corrosion rate of rebar HRB335 increases. The corrosion morphologies show strong consistency with the test results of corrosion rate.
\end{abstract}

\section{Introduction}

As one of the most common modern building structures, rebar concrete is widely used in industrial, agriculture, military and civil construction, etc. With the existence of high alkaline concrete pore solution, the concrete usually provides a protective environment for the rebar, forms a layer of protection film, and restrains or reduces its corrosion [1-5]. Nevertheless, with the passage of time and the change of environment, the corrosion of rebar occurs at different extent because of the inrush of chloride and the carbonization of concrete, which leads to the weakening of concrete and thereby continuous engineering accidents. Therefore, the corrosion of rebar has been one of the main factors to influence the durability and cause the failure of concrete structures [6, 7].

However, in designing a concrete structure, the corrosion of rebar is seldom considered and the excellence of concrete is not brought into action in service period. The damage of rebar corrosion and the essentiality of taking protection measures are increasingly attaching more and more attention. The research on rebar corrosion and its effect on the mechanical properties of rebar is increasing [812]. In this paper, the corrosion behavior of rebar HRB335 in concrete structure in simulated concrete pore solution was investigated by corrosion rate calculation and corrosion morphology observation. It is hoped to provide help to understand the corrosion behavior and take effective protection measures for the rebar in concrete structure.

\section{Experimental}

The test material is common rebar HRB35 in concrete structure. The samples have two sizes: short samples $(\Phi 14 \mathrm{~mm} \times 20 \mathrm{~mm})$ used for corrosion morphology observation, and long samples $(\Phi 14 \mathrm{~mm} \times 450 \mathrm{~mm})$ used for corrosion rate calculation. Before corrosion, the samples are polished, cleaned, and rust-removed (for all samples), and weighed by an electron balance (for long samples).

The corrosion media is simulated pore solution in concrete structure, and its composition is saturated $\mathrm{Ca}(\mathrm{OH}) 2$ solution with 0.5 wt.\%, 1.5 wt.\% and 3.5 wt.\% $\mathrm{NaCl}$ (written as 0.5 wt.\%, 1.5 wt.\% and 3.5 wt.\% NaCl solution). The corrosion time is 10, 20 and 30 days, i.e. 240h, 480h and 720h. After corrosion, different treatments are carried out for different samples. For short samples, corrosion morphology observation is made by a scanning electron microscope (SEM, JSM-5610LV) after they are cleaned and dried out. For long samples, corrosion rate calculation is made after they are immersed in thin hydrochloric acid to remove the scale on the surface and weighed again by an electron balance. 


\section{Results}

\section{A. Corrosion rate}

The measuring results of corrosion rates of rebar HRB335 in 0.5 wt.\%, 1.5 wt.\% and 3.5 wt.\% $\mathrm{NaCl}$ solutions are given in Fig.1.

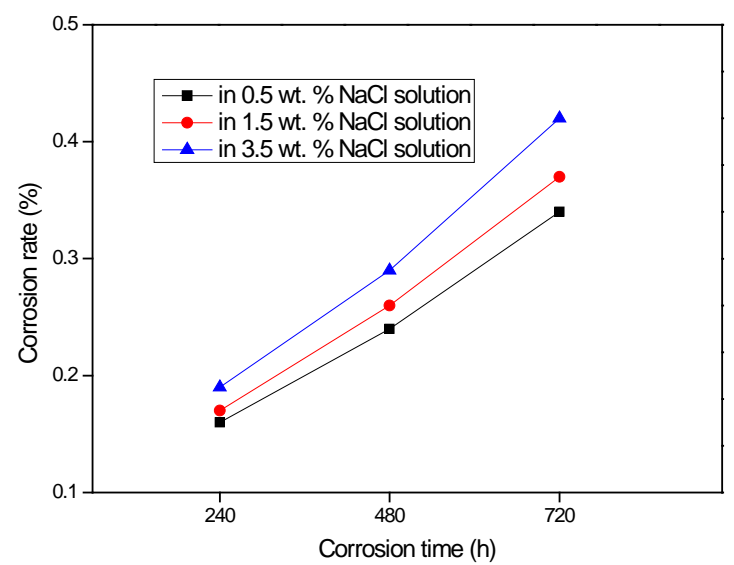

Figure 1 Corrosion rates of rebar $\mathrm{HRB} 335$ in $\mathrm{NaCl}$ solutions

It can be seen that, with the increase of corrosion time from $240 \mathrm{~h}$ to $720 \mathrm{~h}$, the corrosion rate (weight loss rate) of rebar HRB335 increases in each $\mathrm{NaCl}$ solution. Meanwhile, it also can be seen that the corrosion rate of rebar HRB335 is basically in a linear relationship with corrosion time. In addition, with the increase of $\mathrm{NaCl}$ solution concentration, the corrosion rate of rebar HRB335 increases.

\section{B. Corrosion morphology}

The SEM morphologies of rebar HRB335 after corrosion in $0.5 \mathrm{wt} . \% \mathrm{NaCl}$ solution are showed in Fig.2. It can be seen that, with the increase of corrosion time, the character of corrosion morphology is changed. At $240 \mathrm{~h}$, the corrosion is slight and uneven in different areas, and a small quantity of corrosion scale is on the surface (see Fig.2a). At 480h, the corrosion is still uneven, and becomes heavier in level. Some corrosion pits are observed (see Fig.2b). At 720h, the corrosion is uniform (see Fig.2c). In view of the overall situation, with the corrosion time between $240 \mathrm{~h}$ and $720 \mathrm{~h}$, the corrosion develops from some areas to total surface, and becomes heavier and heavier. The corrosion turns from local corrosion into overall corrosion, and the corrosion rate becomes higher and higher. The results are basically consistent with the corrosion rate results in Fig.1.

The SEM morphologies of rebar HRB335 after corrosion in 1.5 wt.\% and 3.5 wt.\% NaCl solutions are showed in Fig.3 and Fig.4. It can be seen that, with the increase of corrosion time, the character of corrosion morphology is also changed. From $240 \mathrm{~h}$ to $720 \mathrm{~h}$, the corrosion develops from some areas to total surface, and becomes heavier and heavier. The corrosion turns from local corrosion into overall corrosion, and the corrosion rate becomes higher and higher. The results are also basically consistent with the corrosion rate results in Fig.1.

In addition, according to Fig.2, Fig.3 and Fig.4, it can be seen that the corrosion morphologies of rebar HRB335 show some changes with the concentration of $\mathrm{NaCl}$ solution. In other words, the corrosion time is not the decisive factor to the corrosion morphology of rebar HRB335. The corrosion morphology changes with the corrosion time and the concentration of $\mathrm{NaCl}$ solution. At the same corrosion, the corrosion becomes heavier in the higher concentration of $\mathrm{NaCl}$ solution. The corrosion morphologies show strong consistency with and the test results of corrosion rate.

From the micro perspective, corrosion is an electrochemical reaction in the surface of rebar, and turn iron and steel material into rust. The higher concentration of corrosion media can accelerate the progress and rate of the corrosion reaction of rebar, which changes the surface morphology and the 
microstructure. After corrosion, the effective section area of rebar is smaller, which decreases the load that it can resist. Meanwhile, with the existence of the inner stress, the corrosion will also change the internal structure. These will affect the mechanical properties of rebar.

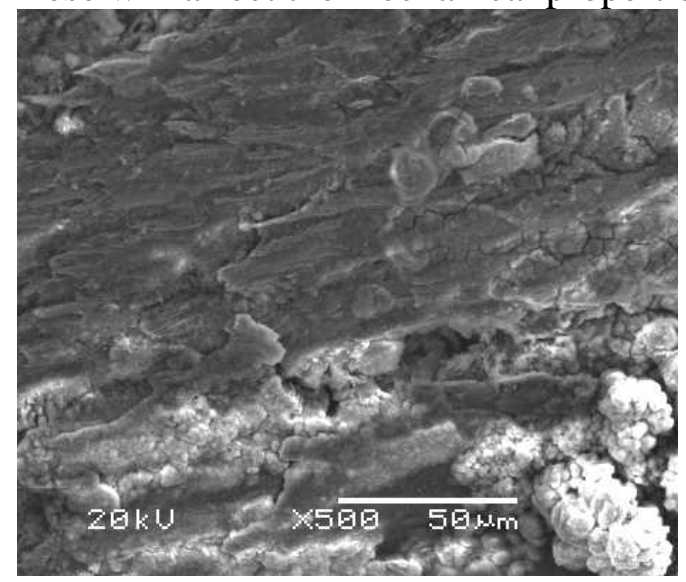

(a) $240 \mathrm{~h}$

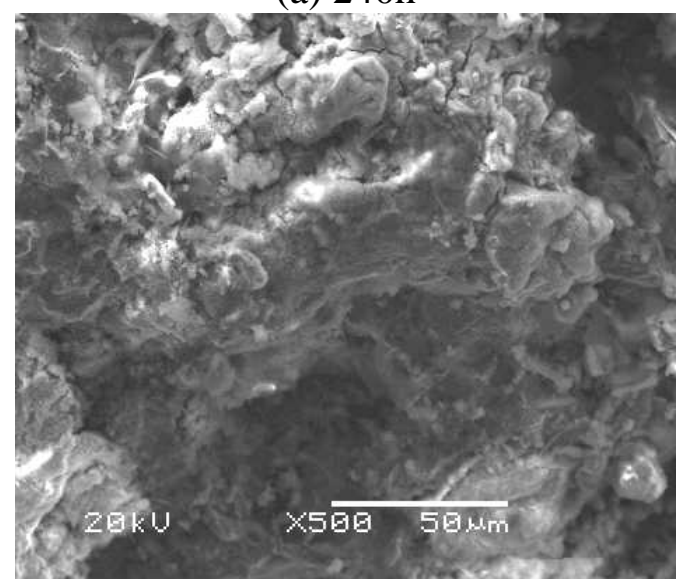

(b) $480 \mathrm{~h}$

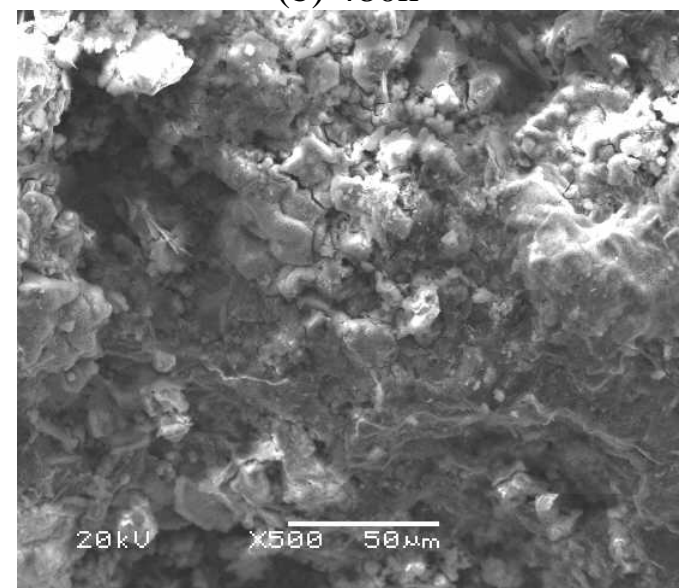

(c) $720 \mathrm{~h}$

Figure 2 Corrosion morphologies of rebar HRB335 in $0.5 \% \mathrm{NaCl}$ solution 


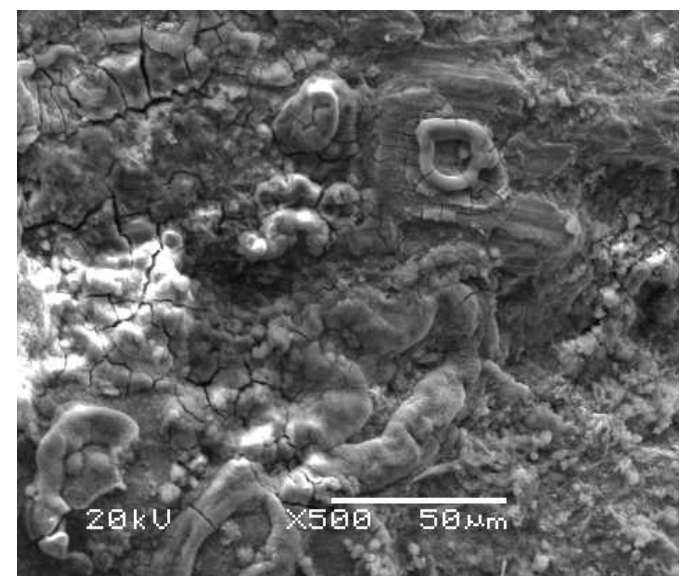

(a) $240 \mathrm{~h}$

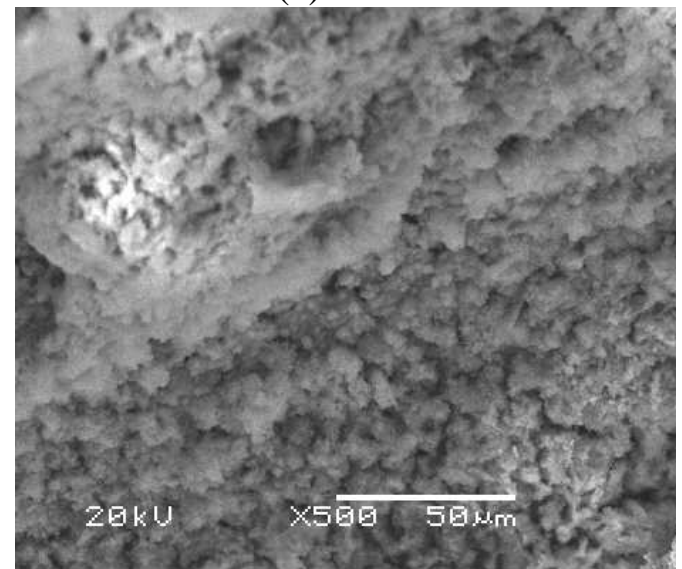

(b) $480 \mathrm{~h}$

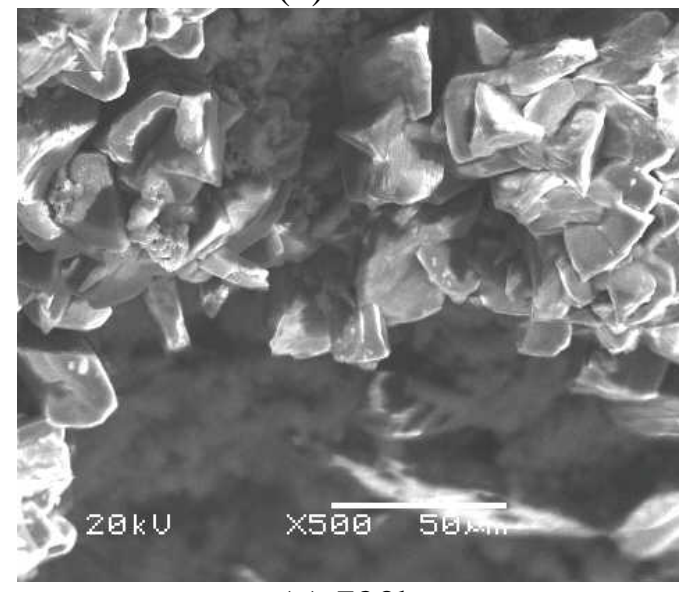

(c) $720 \mathrm{~h}$

Figure 3 Corrosion morphologies of rebar HRB335 in 1.5\% $\mathrm{NaCl}$ solution

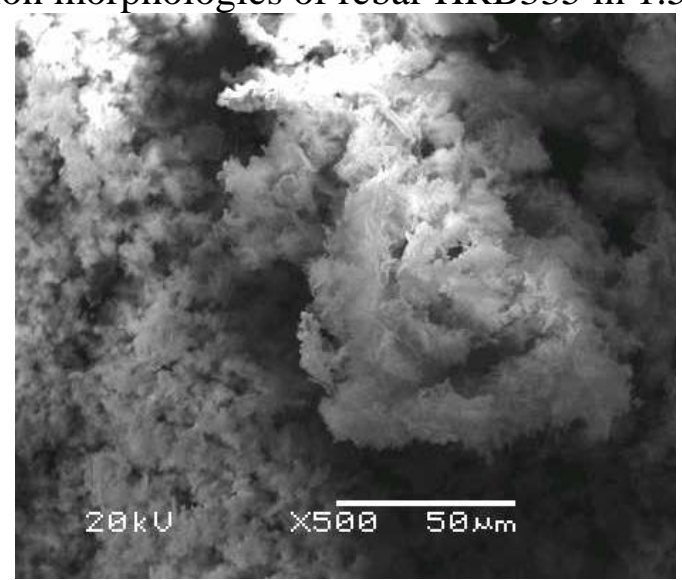

(a) $240 \mathrm{~h}$ 


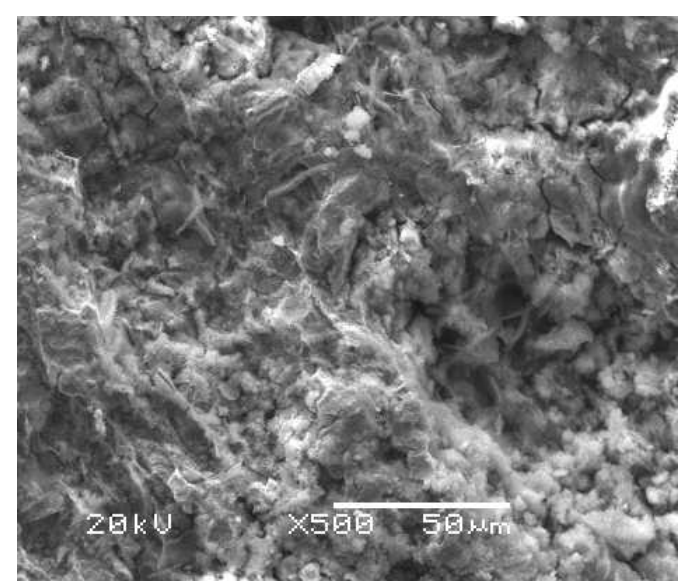

(b) $480 \mathrm{~h}$

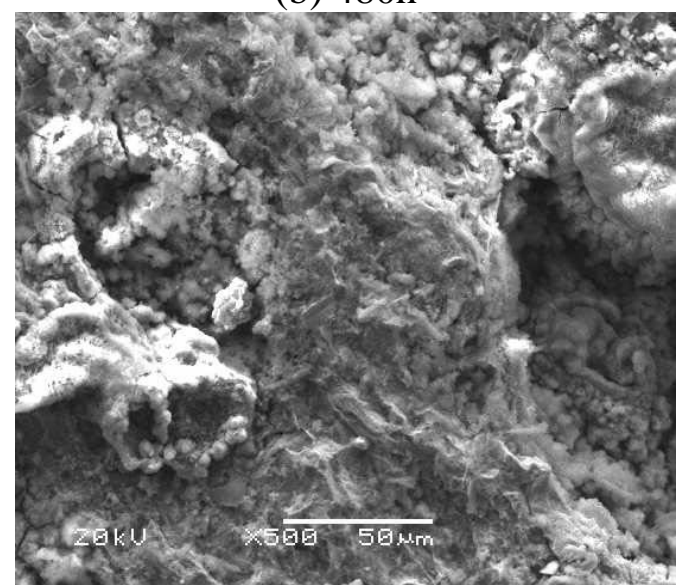

(c) $720 \mathrm{~h}$

Figure 4 Corrosion morphologies of rebar HRB335 in 3.5\% NaCl solution

\section{Discussion}

In fact, the corrosion of rebar in concrete structure is an electrochemical process. Its principle is as same as that of natural corrosion of iron and steel in the air, solution, and soil. It is still an oxidationreduction reaction in essence. It is carried out at the same time through anodic reaction (oxidation reaction) and cathodic reaction (reduction reaction) respectively.

When there is water on the surface of rebar, Fe ionizes in the anode and oxygen reduces in the cathode in the solution. The reactions occur at same rate, and their equations are as follows:

$$
\begin{gathered}
\mathrm{Fe} \rightarrow \mathrm{Fe}^{2+}+2 \mathrm{e}^{-} \\
\mathrm{O}_{2}+2 \mathrm{H}_{2} \mathrm{O}+4 \mathrm{e}^{-} \rightarrow 4 \mathrm{OH}^{-}
\end{gathered}
$$

The whole corrosion process is combination of anodic reaction and cathodic reaction. As a result of this, $\mathrm{Fe}(\mathrm{OH}) 2$ is formed on the surface of rebar, and $\mathrm{Fe}(\mathrm{OH}) 3$ is further produced by oxidation. The reactions can be written as follows:

$$
\begin{gathered}
2 \mathrm{Fe}+\mathrm{O}_{2}+2 \mathrm{H}_{2} \mathrm{O} \rightarrow 2 \mathrm{Fe}^{2+}+4 \mathrm{OH}^{-} \rightarrow 2 \mathrm{Fe}(\mathrm{OH})_{2} \\
4 \mathrm{Fe}(\mathrm{OH})_{2}+\mathrm{O}_{2}+2 \mathrm{H}_{2} \mathrm{O} \rightarrow 4 \mathrm{Fe}(\mathrm{OH})_{3}
\end{gathered}
$$

And the next step is the formation of $\mathrm{nFe} 2 \mathrm{O} 3 \cdot \mathrm{mH} 2 \mathrm{O}$ (red rust) and $\mathrm{Fe} 3 \mathrm{O} 4$ (black rust), and a layer of rust is formed on the surface of rebar. The volume of red and black rust is increased as four and two times as that of original one respectively. The increased volume of rust produces pressure to the surrounding concrete, causes the concrete crack along the rebar, and leads to the drop of protective layer in pieces. The formation of crack and the drop of the protective layer result in the further heavier corrosion of the rebar, which will lead to the decrease of mechanical properties of rebar. 


\section{Conclusions}

With the increase of corrosion time from $240 \mathrm{~h}$ to $720 \mathrm{~h}$, the corrosion rate of rebar HRB335 in 0.5 wt.\%, 1.5 wt.\% or 3.5 wt.\% NaCl solution increases.

With the increase of $\mathrm{NaCl}$ solution concentration, the corrosion rate of rebar HRB335 increases. The corrosion morphologies show strong consistency with and the test results of corrosion rate.

\section{Acknowledgment}

The financial support of Basic and Frontier Technologies Research Plan of Henan Province in China (No. 122300410348) is gratefully acknowledged.

\section{References}

[1] P. Li, D.X. Zhang, Corrosion and protection of reinforcing steel in concrete structure, Materials Protection. vol. 43, 2010, pp. 44-46. (in Chinese)

[2] Y. Wang, P. Li, H.M. Ning, Application of epoxy-coated reinforcing steel in concrete structure, Hot Working Technology. vol. 39, 2010, pp. 133-135. (in Chinese)

[3] P. Li, Y. Wang, Mechanical properties of rebar HRB400 after corrosion, Advanced Materials Research. vol. 753-755, 2013, pp. 516-519.

[4] Y. Wang, P. Li, Corrosion behavior of reinforcing steel bar HPB235 in NaCl solution, Advanced Materials Research. vol. 287-290, 2011, pp. 738-741.

[5] Y. Wang, P. Li, Effect of corrosion on mechanical properties of reinforcing bar HPB235, Advanced Materials Research, vol. 450-451, 2012, pp. 201-204.

[6] Y.X. Guo, J.X. Gong, Experimental study on corrosion of rebar, Corrosion Science and Protection Technology. vol. 19, 2007, pp. 218-220. (in Chinese)

[7] Z.L. Lu, Corrosion behavior and mechanism of reinforced steel in acidic environment, Journal of Chinese Society for Corrosion and Protection. vol. 27, 2007, pp. 119-123. (in Chinese)

[8] Y. Wang, P. Li, Effect of corrosion on mechanical properties of rebar HRB335, Advanced Materials Research. vol. 753-755, 2013, pp. 539-542.

[9] L. Zeng, S.H. Yang, Y. Zhang, Research of the mechanical property of corrosion reinforcing bars, Henan Science. vol. 23, 2005, pp. 877-879. (in Chinese)

[10] S.H. Yang, L. Zeng, Research of the influence of corrosion for mechanical property of reinforcing bars, Journal of Zhengzhou University (Engineering Science). vol. 26, 2005, pp. 85-88. (in Chinese)

[11] G.X. Ruan, G.Y. Liu, Governance of rebar corrosion in concrete structure, Sichuan Building. vol. 26, 2006, pp. 83-86. (in Chinese)

[12] C. Gui, Experimental research of mechanical performance of corroded reinforcement, Shanxi Architecture. vol. 33, 2007, pp. 161-162. (in Chinese) 